\title{
Os mapas como operadores na gênese da cidade espraiada. Desconstrução e semiose cartográfica na análise das plantas da cidade de São Paulo entre 1877 e 1930
}

\author{
Eliane Kuvasney*
}

Recebido 3 de julho de 2018; aceito 19 de dezembro de 2018

\begin{abstract}
The present work deals with the cartography produced about the city of São Paulo between 1877 and 1930 and how this cartography interfered in the way the city was seen and constructed in the period. We begin from the configuration of the metropolitan urban and its extension, so that the questions which guided the research revolved around the city's sprawling's logic. The city was designed for such structure or was it a product of the real estate market? Is this spreading due to socio-spatial inequalities or is it one of its causes? And, finally, if the maps interfered in the production of the sprawled city. Through a geo-historical approach and methodology of New History of Cartography map analysis, which constitutes in the deconstruction of cartographic objects through the understanding of the context in which they were elaborated, the thesis was developed. Therefore, the first part of the work is the contextualization of the period through existing bibliography, in addition to the analysis of the São Paulo City Hall's minutes and annals, and the main deputies' and mayors' reports, aiming the comprehension of the period and the way in which the municipal patrimony - as lands belonging to the municipality — was being appropriated by the real estate market in the city's construction, while obeying the code of posture that, since 1875 , required that the municipality was mapped. With the objective of analyzing whether the maps would have performance capability in the geographic space, that is, if they acted as operators in the construction of the sprawled city, we also opted for unfolded analyzes of cartographic semiosis for a better understanding of the phenomena of
\end{abstract}

* Doutora em Geografia Humana pela Universidade de São Paulo, e-mail: ekuvas@gmail.com 
self-reference and iconization. From the analysis of the three series of the city's maps it was possible, through the deconstruction and resignification of the map in its series, and the analysis of its self-referential aspects, to arrive at the genesis of the image of the city's sprawling — from the 1897 plant — and its unfolding.

Key words: Geo-history, Cartography, São Paulo, space operators, self-reference, iconization.

\section{Resumo}

O presente trabalho trata da cartografia produzida sobre a cidade de São Paulo entre 1877 e 1930 e de como essa cartografia interferiu na forma como a cidade foi vista e construída no período. Partimos da configuração do urbano metropolitano e de sua extensão, de forma que as questões que nortearam a pesquisa giravam em torno da lógica do espraiamento da cidade: se ela foi pensada para ter essa característica ou foi sendo construída ao sabor do mercado imobiliário, ou se o espraiamento é causa ou consequência das desigualdades sócio-espaciais e, por fim, se os mapas interferiram na produção da cidade espraiada. Através de abordagem geohistórica e da metodologia de análise de mapas da Nova História da Cartografia, que constitui na desconstrução dos objetos cartográficos por meio da compreensão do contexto em que foram elaborados, desenvolveu-se a tese. Por isso, a primeira parte do trabalho é a contextualização do período na bibliografia existente, além das análises das atas e anais da Câmara Municipal de São Paulo, e dos relatórios de intendentes e prefeitos, visando compreender o período e a forma como o patrimônio municipal — as terras pertencentes à municipalidade - foi sendo apropriado pelo mercado imobiliário na construção da cidade, ao mesmo tempo em que não se obedecia o código de posturas que, desde 1875 exigia que o município fosse mapeado. Com o objetivo de analisar se os mapas teriam capacidade de agir "com desempenho" no espaço geográfico, se os mesmos atuaram como operadores na construção da cidade espraiada, optou-se também por análises desdobradas da semiose cartográfica com o propósito de compreender os fenômenos da autorreferencia e da iconização. A partir da análise de três séries de mapas da cidade foi possível, através da desconstrução e da ressiginificação dos mapas em suas séries e da análise de seus aspectos autorreferenciais, chegar à gênese da imagem do espraiamento da cidade — a partir da planta de 1897 — e seus desdobramentos.

Palavras-chave: Geo-história, Cartografia, São Paulo, Operadores Espaciais, Autorreferencia, Iconização.

\section{Resumen}

El presente trabajo trata de la cartografía producida sobre la ciudad de São Paulo entre 1877 y 1930 y de cómo esa cartografía interfirió en la forma de como la ciudad fue vista y construida en el período. Se parte de la configuración del área urbano- 
metropolitano y de su extensión, de forma que las cuestiones que guiaron la investigación giraban en torno a la lógica de la expansión de la ciudad: si fue pensada para tener esa característica o se fue construyendo según el mercado inmobiliario, o si la expansión fue causa o consecuencia de las desigualdades socio-espaciales, y finalmente, si los mapas interfieren en la extensión de la ciudad. A través del enfoque geohistórico y de la metodología de análisis de mapas de la Nueva Historia de la Cartografía, que constituye en la deconstrucción de los objetos cartográficos por medio de la comprensión del contexto en que fueron elaborados, se desarrolló el presente trabajo. La primera parte del trabajo, presenta la contextualización del período a partir de la bibliografía existente, además de los análisis de las actas y anales del Ayuntamiento de São Paulo, y de los informes de intendentes y alcaldes, con el fin de comprender el período y la forma en que el patrimonio municipal - las tierras pertenecientes al municipio - fueron apropiadas por el mercado inmobiliario en la construcción de la ciudad, al mismo tiempo que no se obedeció el código de situación que, desde 1875 exigía que el municipio fuera mapeado. Con el objetivo de analizar si los mapas tendrían capacidad de actuar "con desempeño" en el espacio geográfico, si los mismos actuaron como operadores en la construcción de la ciudad, se analizó la cartografía del período con el propósito de comprender los fenómenos de la autorreferencia y de la iconización. A partir del análisis de tres series de mapas de la ciudad fue posible, a través de la deconstrucción y de la resignificación de los mapas en sus series y del análisis de sus aspectos autorreferenciales, llegar a la génesis de la imagen de extensión de la ciudad — a partir de la planta de 1897- y su desarrollo.

Palabras clave: Geo-historia, Cartografia, São Paulo, Operadores espaciales, Autorreferencia, iconización.

\section{Um olhar sobre a São Paulo do passado por meio da cartografia}

Esta foi uma tese desenvolvida no âmbito da geografia, mas nossa análise situa-se no passado da metrópole paulistana (1870-1930) e, por isso, tratou-se de pesquisa desenvolvida a partir de um quadro geo-histórico, tendo como centro a organização espacial produzida. ${ }^{1}$

A opção pela geo-história visava integrar a temporalidade ao objeto de pesquisa. No caso, o território do município de São Paulo, através de uma perspectiva diacrônica, analisando os fenômenos em sua evolução no tempo. Nessa abordagem, a escala

1 O texto é um resumo estendido da tese defendida no âmbito do Programa de Pós-Graduação em Geografia Humana da FFLCH-USP, em 2017: A representação da cidade de São Paulo nos albores do século XX. Os mapas como operadores na construção da cidade espraiada. Disponível em:

</http://www.teses.usp.br/teses/disponiveis/8/8136/tde-26042018-135249/pt-br.php/> 
espacial é também temporal, sendo necessário, portanto, analisar qual a extensão do fenômeno, de forma a refletir sobre sua duração. Descrever e interpretar a organização espacial de uma cidade tem, nos diversos recursos de representação, bons aliados metodológicos. Aqui irá se expor interpretações derivadas de um "saber visual" muito desenvolvido nas cidades, que é o mapa (Fonseca et al., 2016).

Jaime Oliva e Fernanda Fonseca (2011), ao refletir sobre a questão da urbanidade em São Paulo, afirmam que não são comuns estudos sobre a metrópole que partam de elaborações teóricas sobre as cidades e que, em geral, "as cidades não são suficientemente conceituadas, pois costumam ser tratadas como cenários onde processos mais fundamentais se desenrolam". Assim, estudos que levem em conta a

dimensão espacial (essa vista como uma das dimensões do social) é algo raro nos estudos urbanos da metrópole de São Paulo de um modo geral, e na Geografia também. Do mesmo modo, incluir a Cartografia e a representação das paisagens relativas às cidades como elementos que operam (e não apenas registram) sobre esses espaços, e em razão disso, utilizálas como meios relevantes para interpretar as cidades também não é comum (Oliva e Fonseca, 2011, p.14).

Tendo em conta a questão levantada pelos autores sobre a ausência de trabalhos que investigassem como a cartografia operou na configuração espacial da metrópole, nossas análises, adotando a abordagem geo-histórica, seguiram a metodologia da Nova História da Cartografia, ou seja, a desconstrução dos mapas, por meio da metodologia proposta por J. Brian Harley $(1987,2005)$. Mas, ao observar-se que os mapas também são instrumentos miméticos que vão além de seus fins pretendidos e se elevam acima das questões culturais que originalmente os moldaram, optou-se também por análises desdobradas da semiose cartográfica (desenvolvida por Emanuela Casti, 1998, 2005) para uma melhor compreensão dos fenômenos da autorreferencia ${ }^{2}$ e da iconização. ${ }^{3}$ Assim, os mapas foram analisados enquanto sujeitos das ações de transformação do território.

Jean-Marc Besse, numa reflexão acerca da cartografia e do pensamento visual, nos lembra da importância do mapa, ao afirmar que:

o mapa é objeto e ato de poder ao mesmo tempo. Por um lado, o mapa leva a marca de uma intenção, de um interesse de origem econômica, política, ideológica, até mesmo científica, que vai orientar a seleção das informações, seguida da sua apresentação cartográfica. Mas, por outro lado, o mapa tem o poder, como muitas outras imagens, de orientar as decisões da sociedade e da cultura, simplesmente porque formata a visão do mundo sobre a qual se baseiam essas decisões (Besse, 2006, p. 5, trad. nossa).

2 Autorreferência, segundo Casti (2005) é a capacidade de um mapa ser aceito como tal e, ao mesmo tempo, desempenhar um papel na comunicação que é independente das intenções do cartógrafo que o produziu.

3 A iconização, segundo a mesma autora, trata-se da capacidade do mapa de estabelecer como o território deve ser concebido e experimentado. 
Nesta concepção, fundada na Nova História da Cartografia (NHC), o mapa é visto como um objeto de saber-poder (J. B. Harley, baseado em Michel Foucault), mas também é visto como sujeito, que formata visões, e é capaz de operar transformações. Assim, tendo essa última afirmação como hipótese, mobilizaram-se mapas históricos com o objetivo de investigar se tais imagens tiveram o poder de moldar - mesmo que indiretamente - a realidade do território, ou ainda se elas teriam promovido o que percebemos hoje como uma naturalização do espraiamento da cidade. Nesse sentido, e pensando no que existe sobre a cidade de São Paulo nos albores do século XX, o que se narra convincentemente é internalizado e, consciente ou inconscientemente, informa algumas ações, projetos, planos e políticas. Assim, é importante rever as imagens que partilhamos sobre o período que a historiografia denominou de República Velha porque elas nos mostram permanências de representações que hoje criticamos.

\section{Os mapas como operadores em diferentes mises en intrigue do espaço}

Os operadores espaciais são, conforme definido por Michel Lussault (2007, p. 19), “entidades que possuem uma capacidade de agir com 'desempenho' no espaço geográfico das sociedades interessadas". Existem diferentes tipos de operadores humanos (os indivíduos ou o coletivo) e não humanos. Esse mesmo autor (idem, p. 150) afirma que os operadores não humanos são designados e construídos como tais pelos humanos e estes últimos definem sempre os limites que os separam do que lhes é externo, ao mesmo tempo em que elaboram todos os métodos de apreensão — pelos demais humanos - dos não humanos, de forma que há, evidentemente, sempre uma parte de humanidade nos operadores não humanos. Estes, a partir das ações nas quais se inscrevem, às vezes são dotados pelos operadores humanos de uma espécie de caráter e, quase personificados, tornam-se então o que foi denominado de "quase personagens". Nessa investigação partimos da hipótese que determinados mapas se tornam mais que "simples protagonistas", ou seja, tornam-se "quase personagens", apesar de serem objetos, artefatos. E é aí que entra a semiose cartográfica desenvolvida por Emanuela Casti (1998, 2005). Através da autorreferencia e da iconização estes artefatos deixam de ser simples protagonistas para — dotados de competências enunciativas que os hibridizam - tornarem-se "quase personagens", pois passam a interferir nos arranjos espaciais existentes, desempenhando um papel na comunicação que é independente das intenções do operador que os produziu.

Mapas operando transformações. Essa foi a hipótese do trabalho. Dois autores, Jean-Marc Besse (2014) e Michel Lussault (1995) têm nas teorias de Paul Ricoeur (1913-2005) a base para a explicação do mapa como objeto capaz de operar transformações (o mapa como sujeito da ação). Besse lembra que os atlas nos apresentam 
uma mise en intrigue 4 do espaço, cujo papel é a configuração do espaço geográfico semelhante ao do calendário, da sucessão das gerações e da acumulação dos vestígios documentais — os mapas - para a configuração do tempo histórico. Ele afirma que:

o atlas faz parte dos dispositivos de articulação do espaço em mundo. No atlas, pelas operações de divisão das unidades espaciais e a reunião dos mapas numa sequência ordenada, o espaço geográfico é, por assim dizer, formado e tornado habitável. (Besse, 2014, p. 14, trad. nossa).

Esse autor vê o atlas como um dispositivo ${ }^{5}$ e, por isso, capaz de operar transformações, na medida em que "se apresenta ao leitor como uma configuração objetiva na qual pode se orientar e dar uma significação concreta, neste caso especial, às suas condutas" (idem., ibidem).

Os atlas são grandes narrativas e essas narrativas são estruturadas por meio de mapas. Neles, o espaço geográfico ordena-se e desenvolve-se de acordo com uma hierarquização de escalas relativamente clara em um esquema intelectual geral que há muito tempo se impõe nos atlas geográficos modernos: começam pelo mapamúndi, com uma visão geral do globo, depois abordam alternadamente as partes do mundo (por exemplo: Europa, Ásia, América, África), que são divididos em países e esses países divididos em regiões... Uma narrativa do espaço desde Ortelius e seu Theatrum orbis terrarum.

Já Michel Lussault (1995) nos explica que os projetos urbanísticos, dependentes dos mapas para se concretizarem também constituem em narrativas e que, neles,

a mise en intrigue se escreve menos do que se representa visualmente, pois a narrativa é, acima de tudo, suportada pela iconografia [as plantas, as maquetes etc], que fixa e restringe a palavra, descritiva, explicativa, interpretativa" (Lussault, 1995, p. 171, trad. nossa).

Lussault também lembra que a mise en intrigue faz parte de um todo, por Ricouer denominado de triplo mimesis, que ele transpõe para o processo de elaboração do projeto urbanístico:

Em redor da fase essencial de configuração dinâmica da trama [a mise en intrigue] encontramos primeiro, a montante, uma pré-compreensão do mundo da ação, que é aquela, aqui, da operação proposta/projetada - configuração da trama, ou seja, elaborada a partir do ordenamento proposto - intersecção do mundo do projeto e daqueles dos patrocinadores, usuários, etc (...). É claro que a mediação social, o terceiro nível, se manifesta pouco ou

4 A 'mise en intrigue', para Paul Ricoeur, "consiste em combinar os acontecimentos contados, os episódios, numa totalidade configuracional e a vincular uma história a um narrador" (Louis Panier. Ricouer et la Semiotique. Disponível em: http://halshs.archives-ouvertes.fr/docs/00/35/36/43/DOC/Panier_Ricoeur_semotique.doc Acesso em 28/02/2014.

5 Conforme Giorgio Agamben: "Chamo dispositivo tudo o que tem, de uma maneira ou outra, a capacidade de capturar, orientar, determinar, interceptar, modelar, controlar e assegurar os gestos, as condutas, as opiniões e os discursos dos seres vivos" (Qu'est-ce qu'un dispositif? Rivages, 2007, p. 31, citado por Besse, 2014, p. 9). 
nada durante todo o desenrolar e, além disso, frequentemente influencia os dois outros. Por exemplo, a intervenção do campo político - uma das formas obrigatórias da mediação, porque não podemos esquecer que este não é um jogo de soma zero, que os desafios e as relações de poder são reais, mesmo se a encenação da transação os eufemise... (Lussault, 1995, p. 172, trad. nossa).

Para esses dois autores, a mise en intrigue do atlas ou do projeto urbanístico é orientada pelos mapas, os objetos técnicos ${ }^{6}$ dotados pelos que os inserem em suas respectivas narrativas —os operadores humanos, sejam eles o cartógrafo, o editor ou o colecionador, no primeiro caso, ou os urbanistas, no segundo - de uma capacidade, de uma essência que os transforma —os objetos—em protagonistas daquelas ações. Mas, e quanto à produção da cidade da São Paulo? É interessante retomar o exemplo do fotógrafo Militão Augusto de Azevedo que, ao produzir o álbum comparativo da cidade de São Paulo (1862-1887), com suas vistas urbanas,

foi um dos primeiros produtores, senão o primeiro, que se empenharam na formação de uma imagem moderna para São Paulo, através do meio utilizado para a produção dessas vistas - a fotografia - e, em especial, por buscar apresentar, por meio da montagem de uma sequência de imagens, o próprio processo de modernização da capital provincial (por ele nomeado em suas cartas através do termo 'progresso') (Araujo, 2006, p. 117).

Militão evidentemente produziu uma narrativa da cidade em processo de transformação (sua pré-compreensão do mundo da ação, conforme Ricoeur), pois tinha claramente como objetivo mostrar o "processo de modernização" dessa cidade.

No caso da pesquisa em tela, também se construiu uma mise en intrigue -uma narrativa - cujo enfoque foi a produção da cidade entre o fim do Império e o fim da República Velha (1877-1930), onde pudemos denotar o protagonismo dos mapas, mas no sentido de uma desconstrução da ideia de cidade moderna que o grupo no poder (os velhos comerciantes, os cafeicultores e a emergente burguesia industrial) queria construir. Ao se estabelecer séries de mapas —os produzidos por Jules Martin no fim do Império; os produzidos pela e para a administração municipal entre 1897 e 1930 e os produzidos pela Comissão Geográfica e Geológica de São Paulo (CGGSP) para as exposições - foi possível observar, por meio da contextualização de sua produção, de sua desconstrução e da análise semiótica, que uma parte daqueles mapas foi, de fato, protagonista na organização espacial da cidade de São Paulo. Seu papel na construção da narrativa da modernidade paulistana, ao mesmo tempo que foi esclarecido, foi também desconstruído, de forma a podermos compreender melhor a ação dos demais operadores espaciais. Determinados mapas, no entanto, ao serem

6 Objeto técnico no sentido empregado por Milton Santos: “As técnicas, de um lado, nos dão a possibilidade de empiricização do tempo e, de outro lado, a possibilidade de uma qualificação precisa da materialidade sobre a qual as sociedades humanas trabalham. Então, essa empiricização pode ser a base de uma sistematização, solidária com as características de cada época" (Santos, 2002, p. 54). 
usados para comunicar conjecturas como verdades, passaram a oferecer uma conceitualização do território, deslocaram o processo de comunicação do mapa da descrição para a conceitualização e tornaram-se "quase personagens".

\section{A semiose cartográfica}

A semiose cartográfica desenvolvida por Emanuela Casti $(1998,2005)$ estabelece que um estudo semiótico dos mapas não pode ser separado de um estudo semiótico do território. Ela parte do pressuposto de que o significado social do território se encontra na sua configuração semiótica, o território constitui-se linguisticamente como um conjunto de designadores que têm um valor cognitivo e ao mesmo tempo comunicativo (Turco, 2006). Essa abordagem sustenta que os mapas se baseiam numa meta-semiose (ou semiose de segundo nível), uma vez que sua linguagem é moldada na linguagem territorial (ou semiose de primeiro nível). Nesse sentido, a autora afirma que

dois aspectos da interpretação cartográfica devem ser observados: (1) que o nome dado no mapa é visto não como um signo entre muitos outros, mas como aquele pelo qual toda a informação cartográfica é organizada; e (2) que a semiose —o processo pelo qual a informação é produzida e transmitida - ocorre na presença de um intérprete, que tem uma dupla função como agente territorial e como alguém que se comunica dentro de uma dada sociedade. (Casti, 2005, p. 5, trad. nossa)

A semiose cartográfica está apoiada na abordagem hermenêutica e trabalha com a ideia do mapa como instrumento de intervenção entre a sociedade e o território, partindo da premissa de que os mapas, nesse tipo de relação, desempenham papel crucial. Essa autora afirma que:

a hermenêutica foca no papel dos mapas como agentes capazes de implantar informações autorreferenciais para moldar efetivamente a intervenção humana no território, ou seja, os mapas lidam com um espaço geográfico complexo, reformulando-o como um espaço cartográfico com base na ação que é executada" (Casti, 2005, p. 5, trad. nossa).

Para compreendermos melhor a semiose cartográfica (Figura1), Casti (2005) lembra que essa abordagem vê o território não exclusivamente como um dado empírico, mas como um processo pelo qual uma sociedade transforma o espaço natural e o impregna de sentido e significado. Assim, o processo de territorialização — por ela entendido como "multiplicidade de procedimentos em ação sobre o território"—pode ser dividido esquematicamente em três grandes categorias:

1. Denominação: envolve o controle de símbolos, ou seja, as operações voltadas para a modelagem intelectual e apropriação do território: a atribuição de nomes a pontos na superfície da terra, que são assim identificados como lugares. 
2. Reificação: o exercício do controle material, isto é, a construção física e apropriação do território.

3. Estruturação: a criação de contextos operacionais para a execução de projetos sociais.

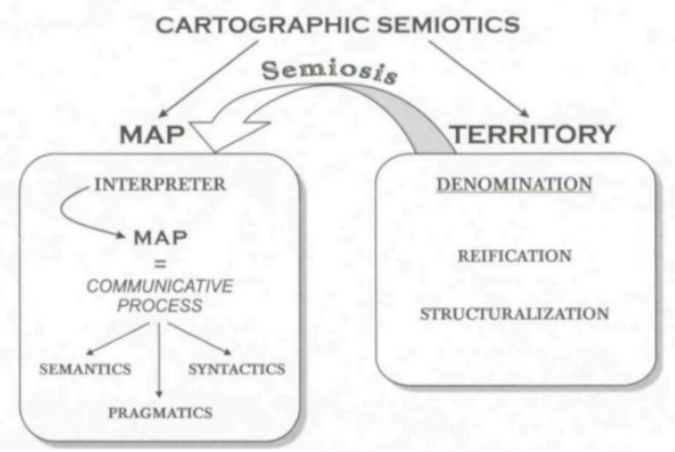

Figura 1. A transferência da semiose territorial e o estabelecimento da meta-semiose cartográfica. Fonte: Casti, E. "Towards a Theory of Interpretation: Cartographic Semiosis", Cartographica, vol. 40, nº. 3, 2005, p. 7).

\section{A importância da denominação: os designadores}

Casti afirma que a denominação é um processo complexo em que diferentes significados entram em jogo, dependendo do tipo de designador usado e sobre os tipos de valores que pode transmitir. "Quando usamos este termo, estamos nos referindo à atribuição de nomes que refletem os valores da sociedade que os executa" (Casti, op.cit, p. 5). Ela os classifica como "aglomerados de conceitos" que localizam/identificam, no território, os valores culturais sobre os quais o funcionamento da sua sociedade se baseia. Por isso ela os classifica de "designadores" e não de topônimos.

A análise denominacional foi emprestada da semiologia da territorialidade desenvolvida por Angelo Turco, nos anos noventa. ${ }^{7}$ Segundo esse autor,

a denominação aparece como um conjunto de procedimentos que asseguram o controle intelectual do território. (...) O mais elementar dos saberes territoriais é o referencial. Ele está incluído nos designadores que fixam uma referência sobre a superfície terrestre: indicando com precisão a posição de um lugar, em absoluto ou em relação a outros lugares, esses designadores possibilitam o posicionamento dos sujeitos, dos objetos e dos eventos, consentindo assim às pessoas que se desloquem no espaço sem correr o risco de perder-se. (...) [Quanto ao saber] do tipo simbólico (...) os designadores não se limitam a fixar no terreno uma referência, mas transferem para a superfície terrestre crenças generalizadas,

7 Ver, entre outros: Turco, A. (1988). Verso una teoria geografica della complessitud. Milano: Unicopli e Turco, A. (1994). Semiotica del territorio: congetture, esplorazioni, progetti. Rivista Geografica Italiana, [S.1.], nº. 101, pp. 365-383. 
baseadas em valores socialmente produzidos e difusamente compartilhados. (...) Uma ulterior forma de saber territorial é a performativa (...) os designadores são avaliados e julgados tendo por base um critério de verdade (...) e encarregam-se de colher, do modo mais preciso e aprofundado possível, os traços do ambiente no qual vivem os diversos povos, de maneira compatível com cada uma de suas tradições, com cada um dos respectivos projetos sociais (Turco, 2006, pp. 6-8).

Sendo os designadores descrições abreviadas da realidade, "aglomerados de conceitos", Casti afirma que a significação cartográfica deve ser pensada levando-se em conta a clássica distinção semiótica entre codificação denotativa ou primária e codificação conotativa ou secundária. ${ }^{8}$ Assim, o primeiro nível de leitura é o do designador referencial, que é explicitamente codificado para criar um quadro referencial, "um sentido evidente e superficial" (exemplos da autora: do Grand Canyon, Colorado, ou da Quinta Avenida, em Nova York). O segundo nível de leitura torna-se necessário para designadores simbólicos e performativos, "porque aqui devemos reconhecer a sedimentação de valores culturais, técnicos e 'históricos' [São Francisco, Hot Springs Mountain, Nova York, respectivamente], gerados por uma sociedade que só pode ser entendida através de um nível mais profundo de investigação".

Sintetizando o peso da denominação na semiose cartográfica, Casti, ao discorrer sobre a importância da análise dos designadores simbólicos e performativos que mudam dependendo do contexto social ou político, argumenta que o mapa não é apenas o lugar dentro do qual se realiza a apropriação intelectual do território. É também uma projeção denominativa porque transmite o(s) significado(s) guardado(s) no designador por meio de outros códigos, chamados substitutos denominativos. É função comunicativa que desempenham e porque assumem alguns dos valores/significados a serem transmitidos e os comunicam como significantes. Um substituto denominativo pode ser qualquer figura, número, cor ou mesmo a posição do nome no mapa, destinada a tornar explícita a qualidade do objeto representado no mapa. (Casti, 1998, p. 65 e Casti, 2005, p. 6).

Dessa forma, o mapa carrega um complexo sistema de informações envolvendo diferentes códigos, o que faz dele um hipertexto, uma linguagem multi-estrutural e, "como tal, desempenha um papel naquilo que ele comunica de uma forma autorreferencial", pois o uso de várias estruturas facilita o transporte de informações e a interrelação entre diferentes códigos traz o que pode permanecer obscurecido em um código individual. (idem, p. 6). Uma constatação de Casti (2005) sobre esse processo é que o designador, ao impor uma hierarquia entre os substitutos (figura, número, cor, posição), é o cerne do processo pelo qual a informação é realmente produzida.

8 Codificação denotativa $=$ sentido literal. Codificação conotativa $=$ sentido figurado. 


\section{Ícone cartográfico $x$ autorreferência}

Ícone, para Casti, é uma figura semiótica que é capaz de produzir informação e processá-la num sentido comunicativo - diferente de outras conceituações semióticas, como para Charles S. Peirce (2005), nas quais o ícone é um signo habilitado a representar seu objeto meramente em função de suas qualidades. Segundo Casti (2005), o ícone cartográfico toma o referente do designador, o modela de alguma forma e depois o introduz na troca de comunicação via mecanismos auto-produtivos; o ícone toma o designador e o envolve com determinado conteúdo, estabelecendo assim o modo como ele pode servir na práxis territorial. Assim, uma vez colocado sobre a folha, o ícone age de duas maneiras sobre o designador: primeiro, oferece uma representação figurativa de sua localização-e assim fortalece sua referencialidade (denota); segundo, realça certos aspectos, cuja importância é determinada por um contexto social particular (conota).

O uso de procedimentos figurativos [denotativos e conotativos] na criação de tais ícones não só desenvolve a informação comunicada pelos designadores, mas também a intensifica. Tais procedimentos são: a organização espacial, na qual a topografia serve para reforçar a natureza referencial do mapa, trabalhando assim a um nível denotativo; a figuração propriamente dita, na qual os códigos visuais são utilizados para realçar as características distintivas do referente; e a iconização, que combina os resultados da organização espacial e da figuração e impregna o designador com implicações sociais ou valores. O resultado é que este último se torna simbólico e/ou performativo (Casti, 1998, p. 70).

O excerto acima esclarece duas coisas: 1) que os ícones não mostram a realidade como ela é. "Em vez disso, eles mostram como ela aparece dentro de uma teoria particular do mundo" (Casti, 2005, p. 10), por meio da visão particular de quem o produz; e 2) é pela ação dos ícones que o que é representado torna-se conceituado e é comunicado por um processo dinâmico o qual oferece uma visão particular do mundo-a visão do cartógrafo. Assim, o sistema icônico baseia-se na capacidade do mapa de transmitir os valores culturais atribuídos ou investidos em um território específico.

Diferentemente do ícone cartográfico, o termo autorreferencia indica a capacidade de um mapa ser aceito como tal e, ao mesmo tempo, desempenhar um papel na comunicação que é independente das intenções do cartógrafo que o produziu (Casti, 1998 e 2005, trad. nossa).

Esta autorreferencia é o resultado do tipo de sistema comunicativo usado e da ação do ícone na denominação em desenvolvimento. Nomes, formas e cores —em suma, toda a linguagem do mapa - desempenham um papel nesse mecanismo "autogerador". (Casti, 2005, p. 10). 
Então, o que faz com que o conjunto de ícones cartográficos contidos no mapa, que são produto da visão particular de quem o produziu, se torne autorreferente, desempenhe um papel na comunicação que é independente das intenções de quem o produziu? Como o mapa se torna capaz de condicionar a informação sobre o que retrata?

O mapa torna-se autorreferencial porque se mostra capaz de condicionar a informação sobre as coisas que retrata. Isso significa que, uma vez criado, o mapa é um sistema de signos dotado de vida própria; ela se desenvolve independentemente do que o precedeu e das intenções por trás de sua criação original (idem, ibidem, grifos meus).

Além desse aspecto chamado de "interno" pela autora, ela chama a atenção para o fato de a interpretação do mapa estar "ligada à sedimentação de documentos cartográficos ao longo do tempo e à experiência acumulada das pessoas chamadas a lêlos", ou seja, esses dois fatores — sedimentação e experiência- pré-definem o que é um mapa e influenciam o modo como ele é percebido, construindo uma memória de mapas dentro da sociedade. Essa memória, por sua vez, significa que estes intérpretes do mapa

trabalham dentro de uma codificação que já aconteceu, e a sedimentação ao longo do tempo consolidou as várias atribuições de sentido e significado. Da mesma forma, a conexão entre os signos obedece às regras de percepção visual. A informação transmitida não é a soma do que é transmitido por cada ícone, mas o resultado da interação entre essas informações. Em suma, a interpretação de um mapa baseia-se no reconhecimento das formas pelas quais um mapa se define como tal (idem, ibidem, grifos meus).

O paradoxo da autorreferencia é o fato de que os mapas, como modelo, não podem duplicar a realidade, mas podem substituí-la. Casti (2005, p. 10) afirma que "o mapa não se oferece como território; ele realmente apresenta-se como existindo em um nível mais elevado do que a realidade bruta" e, a partir do momento em que os mapas passam a transformar conjecturas em verdades, eles se tornam objetos icônicos.

\section{O território mimetizado. O processo de iconização do mapa.}

A pergunta que se faz aqui é: a mensagem comunicada pelo mapa pode substituir a verdade? De acordo com Casti (2005), isso ocorre porque no processo de iconização, o significado gerado por um mapa é introduzido em um circuito de comunicação explorando as principais funções do próprio mapa: a descrição - as características do território que poderiam ser percebidas pela via da observação direta do mundo real - e a conceitualização — aplicando as categorias de representação (que incorporam uma interpretação) para dizer "como o mundo funciona". Dessa forma, o mapa provoca uma mudança na comunicação do nível da descrição para o nível da enunciação: ele se transforma em discurso. 
O resultado é que a confiabilidade atribuída à descrição também é atribuída ao conceito... a iconização promove o uso do mapa como uma teoria em que se pode confiar para avaliar toda a informação envolvida pela ativação de um sistema no qual vários fragmentos de informação e conceitos são feitos para circular infinitamente e em diferentes formas sobre o plano duplo de comunicação cartográfica: descrever e conceitualizar (Casti, 2005, p. 11).

Casti (2005) nos lembra, sobre esse processo, que o fato do mapa ser um mecanismo de representação capaz de mimesis significa que ele tem maior capacidade comunicativa do que o próprio território bruto e, portanto, acaba assumindo o lugar desse território.

A eficácia do mapa como dispositivo mimético vem de sua equação implícita: mapa = território. Esse poder de mimesis, como ressaltado pela análise semiótica da cartografia, é o que permite a um mapa comprometer e alterar o significado de território. (Casti, 2005, p.12)

\section{Desconstrução ou semiose cartográfica?}

O que vemos por meio da meta-semiose é um passo avante nas análises desconstrutivistas propostas por J. B. Harley. O foco principal das análises de Harley, de que os mapas são "imagens carregadas de intenções e consequências que podem ser estudadas nas sociedades de seu tempo", de que mapas são instrumentos de saber-poder, se tornou restritivo na medida em que se observa que os mesmos são "instrumentos miméticos que vão além de seus fins pretendidos e se elevam acima das questões culturais que originalmente os moldaram". Os conceitos de autorreferencia e iconização enriquecem as análises desconstrutivistas, pois trazem nova perspectiva à essas análises.

Em termos metodológicos, prevalece a necessidade de desconstrução do mapa, mas é preciso também decodificá-lo "para encetar uma recodificação que possa revelar seu impacto elaborado na produção e na circulação do significado territorial" (Casti, 2005, p. 7).

\section{Os mapas como protagonistas da modernidade paulistana}

Três séries de mapas da cidade de São Paulo foram analisadas, elaboradas no período de 1870 a 1930 - final do Império e República Velha. Aqui será tratada somente a série de plantas consideradas "oficiais", a segunda série analisada. Segue o endereço das plantas em seus respectivos repositórios digitais para uma melhor visualização:

I. Planta Geral da Capital de São Paulo organizada sob a direcção do Dr. Gomes Cardin Intendente de Obras. 1897. Escala 1:20.000. BNDigital. Disponível em: <http://objdigital.bn.br/objdigital2/acervo_digital/div_cartografia/ cart71701/cart71701.jpg $>$. 
II. Planta Geral da Cidade de São Paulo 1905 adoptada pela Prefeitura Municipal para uso de suas repartições. Levantada e organizada pelo Engenheiro Civil Alexandre Mariano Cococi e Luiz Fructuoso F. Costa Engenheiros da Comissão Geográfica e Geológica. BNDigital. Disponível em: <http://objdigital.bn.br/objdigital2/acervo_digital/div_cartografia/cart523225/cart523225. jpg $>$.

III. Planta Geral da Cidade de São Paulo de 1913. Levantada e organizada pelo Engenheiro Civil Alexandre Mariano Cococi e Luiz Fructuoso F. Costa. Propr. Exclusiva da Cia. Litth. Hartmann-Reichenbach. Escala: 1:20.000. BNDigital. Disponível em: <http://objdigital.bn.br/objdigital2/acervo_digital/div_cartografia/cart520031/cart520031.jpg>.

IV. Planta da Cidade de São Paulo levantada pela Divisão Cadastral da $2^{\text {a }}$ Secção da Directoria de Obras e Viação da Prefeitura Municipal - Edição Provisória approvada pelo Acto n. 972 de 24 de agosto de 1916. APESP. Disponível em: $<$ http://www.arquivoestado.sp.gov.br/site/acervo/repositorio_digital/mapa_carto/BR_APESP_IGC_IGG_CAR_I_S_0202_001_001>.

A série inicia com a planta que é o foco principal das análises sobre a cartografia que se desdobra a partir dela: a planta geral de 1897 (Figura 2) que foi elaborada entre 1896 e 1897 como um projeto da cidade, contendo loteamentos inexistentes naquele momento (dos quais a maioria foi sendo implantada ao longo das décadas seguintes), mas apresentada e comercializada como a planta da cidade daquele ano. $\mathrm{O}$ fato dela ter sido elaborada na escala 1:20.000 e, portanto, ser a primeira a apresentar o rio Tietê em proporções monumentais, além de mostrar a cidade muito além da colina histórica, ainda no século XIX, nos faz refletir sobre sua influência na forma de ver e pensar a cidade desde então. Em primeiro lugar, ela foi comercializada como planta da cidade por meio de anúncios de jornal e utilizada como prova da existência de rua por cidadão comum perante a justiça e, com isso, declarada planta oficial da cidade já em 1913, após a publicação da planta de 1905. Em segundo lugar, as plantas de 1905 e 1913 vão mostrando a implantação dos loteamentos/arruamentos que ali foram colocados, mas de maneira gradual, indicando que os mesmos, a partir de sua aparição em 1897, foram automaticamente autorizados pela Câmara - pois não se localizam discussões sobre eles nas atas e anais da Câmara, indicando a autorreferencialidade daquela planta.

Além disso, pela análise denominacional observou-se que quem elaborou aquela planta "marcou" os loteamentos inexistentes por meio de três formas de nomeação das ruas: nomes em tupi-guarani, nomes de serras e uma terceira, menos perceptível: nomes de pessoas próximas ao grupo que estava organizando a planta (Figura 3). Essas marcas foram desaparecendo conforme os loteamentos iam se estabelecendo e as ruas iam sendo nomeadas através de leis ou atos do prefeito. Mas, alguns daqueles nomes provisórios permaneceram e essas permanências podem ser lidas como autorreferenciais, pois os nomes permaneceram porque estavam no mapa. 


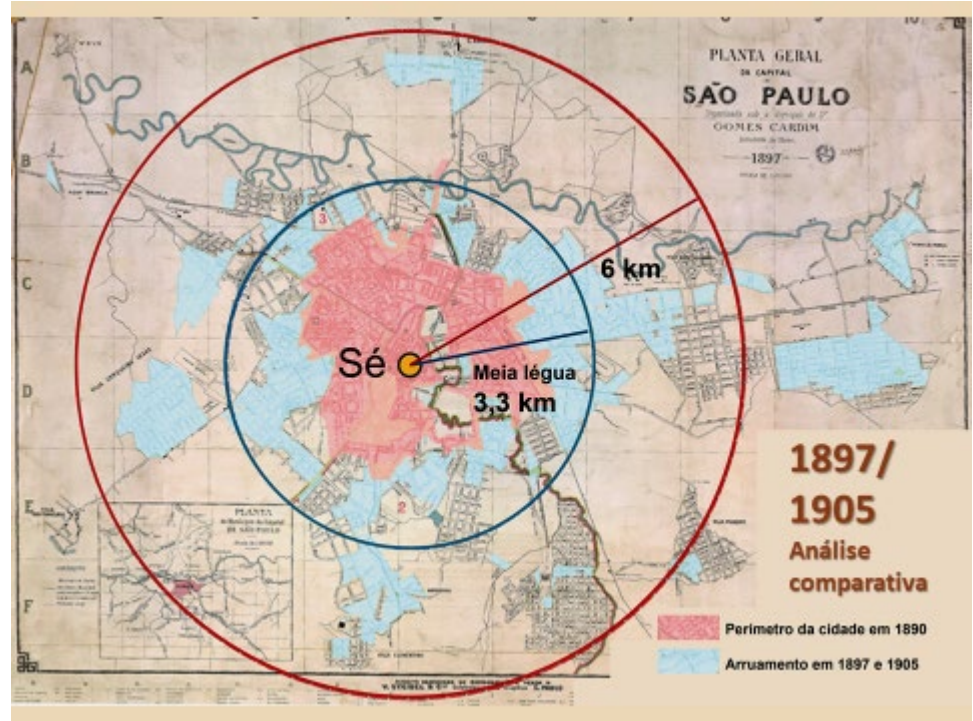

Figura 2. Sobre a planta de 1897 (que era um plano), estão o perímetro da cidade em 1890 (em rosa) e os loteamentos existentes na planta de 1905 (em azul). Os círculos indicam as terras do patrimônio municipal (meia légua do rossio - até o final do Império — em azul e $6 \mathrm{Km}$ —na República — em vermelho).

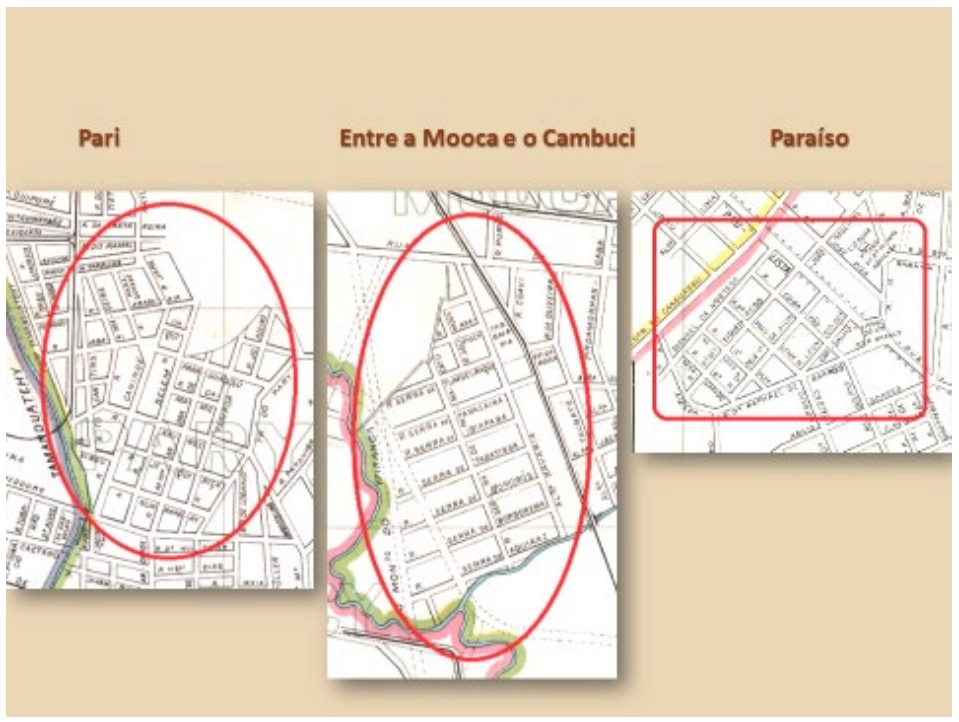

Figura 3. Três loteamentos existentes na planta de 1897 que apresentam ruas com nomes em tupi-guarani (Pari), serras (loteamento entre a Mooca e o Cambuci) e nomes de pessoas próximas ao grupo que elaborava a planta (Paraíso). 
Observou-se também que a planta de 1916 (Figura 4), a única organizada dentro da Diretoria de Obras e Viação (DOV) após a elaboração da planta de 1897, retoma a forma inicial dos loteamentos/arruamentos que observamos estar sendo implementados gradualmente nas plantas de 1905 e 1913, ao mesmo tempo em que inclui um novo substituto denominativo para figurar os terrenos apropriados mas não construídos, as "cercas" (Figura 5), o que acaba nos mostrando duas coisas: a primeira é que a forma, a morfologia da cidade (especificamente do subúrbio) apresentada em 1897 permanecia, ao menos no que se configurava como terrenos apropriados, a espera de valorização. A segunda é que o que dá substância à imagem da cidade espalhada é a cerca e não sua efetiva ocupação, que é mostrada, desde 1905, por meio da mancha que indica a existência de edificações e ela nos mostra que a cidade efetivamente existe no centro e nas bordas daquela forma que se estabelece em 1897.

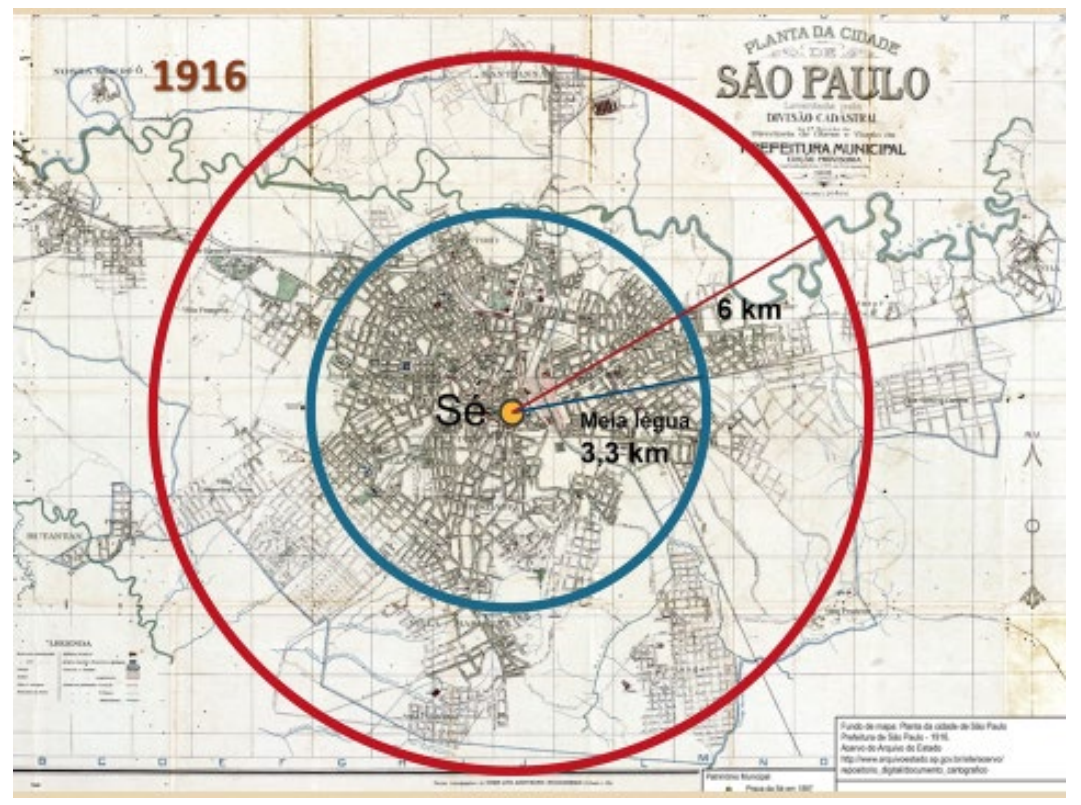

Figura 4. Sobre a planta de 1916 estão os círculos que indicam o antigo rossio (azul) e o patrimônio municipal, de $6 \mathrm{~km}$ (em vermelho). Esta planta apresenta os perímetros central, urbano, suburbano e rural estabelecidos em 1915.

É importante salientar que, como imagens produzidas em contextos diversos, as plantas apresentam marcas relativas a esses contextos. A planta inicial da série de 1897 (Figura 2) traz a marca do que se queria determinar: a área do patrimônio. Ela foi estabelecida em escala 1:20.000 de forma que a totalidade do patrimônio munici- 
pal - representado como um retângulo, conforme demarcado no mapa a ela encartado - nela estivesse representado. E essa forma se estabelece para as plantas seguintes, até a década de 1930, quando a preocupação parece não ser mais apropriar-se dos terrenos do patrimônio, mas tentar reaver parte deles. A planta de 1916, também produzida dentro da DOV é a planta de 1897 melhorada, pois retomam-na incluindo os loteamentos/arruamentos novos, assim como a legislação que demarca os perímetros, além de incluir as cercas, deixando claro para os produtores do mapa e da cidade (o mesmo grupo político no poder) a imagem da cidade que estavam produzindo.

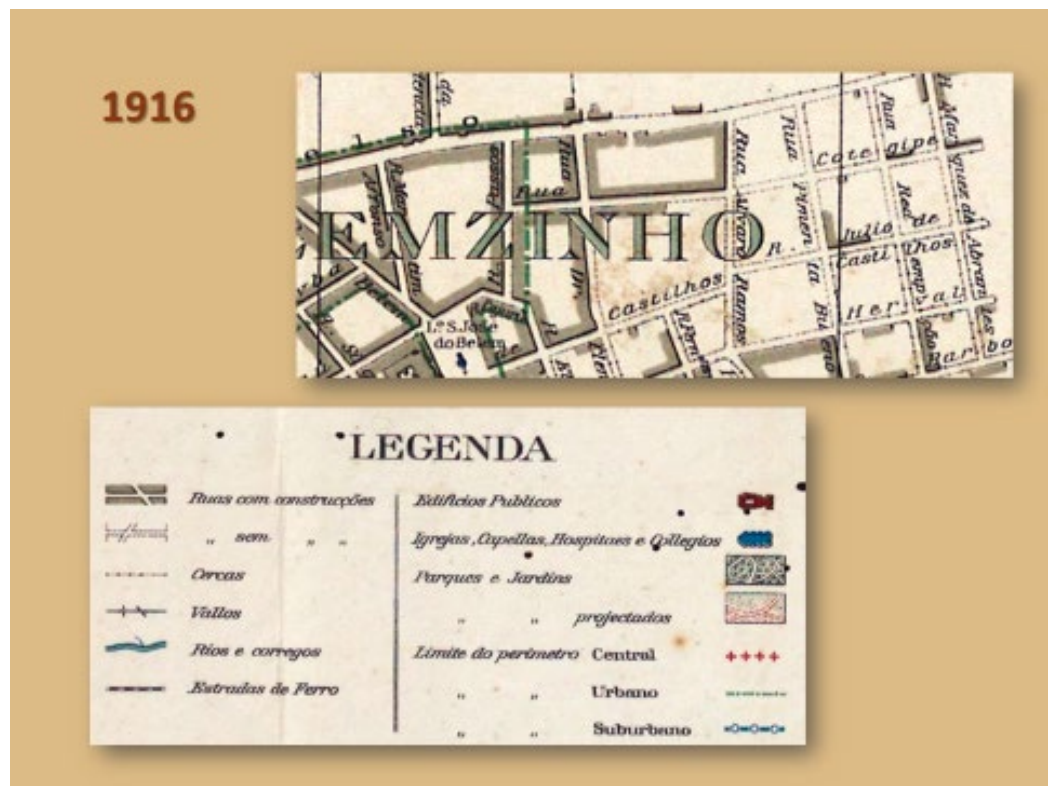

Figura 5. A legenda da planta de 1916 indicando as ruas com e sem construções e as "cercas", e um excerto da planta, mostrando as cercas existentes além do limite leste do perímetro suburbano (em verde), indicando a apropriação das terras do subúrbio como reservas de valor.

Sobre a apropriação do patrimônio público nesse processo, observou-se que a planta de 1897 mostrava o esforço de apropriação privada das terras públicas contidas no raio de $6 \mathrm{~km}$, terras que, na origem foram doadas e estabelecidas como tal, mas que a Câmara, ao longo dos séculos XVIII e XIX tratou como terras a serem apropriadas pelos que dividiam o poder local com os vereadores. Assim, um mercado de terras instalou-se nessa área, bem antes da elaboração de tal planta, mas visível na demarcação dos perímetros de 1915 (na planta de 1916, Figura 4), quando vemos o círculo do antigo rossio (meia légua) totalmente preenchido pela mancha com edificações e, consequentemente, demarcado como perímetro urbano, área que seria submetida a 
partir de então a um maior controle no que se refere a abertura de ruas e construções - e de preços altíssimos dos lotes restantes ou das edificações.

O restante do patrimônio municipal - a área que ia do perímetro urbano até o limite dos $6 \mathrm{~km}$ de raio, demarcada como zona suburbana, foi taxada como área de controle intermediário, garantindo não só a legalidade da quase totalidade dos loteamentos/arruamentos estabelecidos na planta de 1897, mas também estabelecendo regras à abertura de novas ruas, o que garantia maior dificuldade no acesso à terra, com terrenos mais caros, liberando o restante do território municipal — a zona rural — para o mercado imobiliário atuar com mais liberdade, por meio da legislação mais frouxa e, portanto, com terrenos destinados às classes de renda mais baixa, já que não teriam equipamentos urbanos disponíveis. Essa gradação do controle e da fiscalização por perímetros também estava estabelecida para a ação da prefeitura com relação aos melhoramentos: quanto mais distante do centro, menor seria a atuação das diretorias sobre o território, garantindo a tabela de valores diferenciais do mercado imobiliário. Uma prática consagrada desde então.

Além de todos os aspectos autorreferenciais observados na planta de 1897, resumidos na ideia de que conjecturas foram comunicadas como verdades, ou seja, ao ser comercializada como planta da cidade e divulgada como tal inclusive pelo poder público, sua função descritiva - de apresentar as características do território- foi utilizada para apresentar uma conceitualização da cidade "espalhada", o que funcionou no sentido da iconização dessa planta, pois a transformaram na "verdade do território".

A figuração, ou a forma da cidade espalhada deslocou a comunicação do nível da descrição para o da conceitualização. Ela apresentou um novo conceito de cidade, diferente daquele observado nas plantas até então feitas: o conceito de "cidade espalhada", em oposição ao conceito de cidade compacta ou "fortaleza em cima do morro", conforme observado com a conceitualização da cidade feita a partir do mapa de Ourique, de 1842 (ver Kuvasney, 2015). Além disso, a escala de 1:20.000, pela primeira vez utilizada, para conter o patrimônio municipal, se manteve como norma nas demais plantas que, apesar de não seguirem a figuração dos loteamentos da planta de 1897, mantiveram a figuração da cidade espalhada, até que não mais era viável aquela escala, pois a cidade se espalhara para além das terras do patrimônio. O conceito de cidade espalhada se estabeleceu e naturalizou-se como modelo para todo o território do município.

\section{À guisa de conclusão}

O mapa tem maior capacidade comunicativa do que o próprio território e acaba assumindo o lugar desse território, afinal, como disse Bruno Latour (1985, p. 21): "a história das ciências e técnicas é, em boa parte, a dos enganos que permitem conduzir o mundo sobre esta superfície de papel". Essa é a mimetização a que se refere o título 
do capítulo final (O território paulistano apropriado e mimetizado). O fato de o mapa ser um mecanismo de representação capaz de mimesis, significa que ele contém uma equação implícita: mapa = território. E aí chegamos à terceira série de mapas, aqueles que circularam compondo os cartazes da Comissão Geográfica e Geológica de São Paulo (CGGSP) pelas exposições. ${ }^{9}$ Esses cartazes (Figura 6) contrapõem as duas conceitualizações, a de cidade compacta, do século XIX e a de cidade espalhada, do século XX, como a dizer aos milhares de pessoas que os viam nas exposições que a modernidade implicava em progresso e o progresso da cidade implicava em seu espraiamento. Assim, "naturalmente" aceito, este espraiamento também naturalizou a cidade social e territorialmente desigual, transformando o território do município em gigantesca zona urbana, repleta de equipamentos urbanos no centro e que vão rareando conforme nos afastamos dele, até chegar nas periferias distantes, repletas de 'vazios' de equipamentos, vazios repletos de gente, como a recordar as várzeas do início do século XX.

Por fim, uma palavra sobre as metodologias de análise - desconstrução e semiose cartográfica: estas podem enriquecer as análises dos documentos cartográficos numa perspectiva de revisão da importância dos mesmos (foi isso o que procuramos fazer aqui: "desqualificar" a planta de 1897 como planta, utilizada inúmeras vezes como a verdade do território em 1897, quando, na verdade, tratou-se de um plano de cidade futura). Quanto aos processos de desconstrução, se pensarmos nos aspectos autorreferenciais, podemos, ao associar os métodos da semiose cartográfica a eles, analisar como o documento individual ou a série interferiram na forma de pensar e organizar o território (como ocorrido com aquela planta e toda a série que a seguiu). O que vemos por meio da semiose cartográfica é um passo adiante nas análises desconstrutivistas. O foco principal das análises de J.B. Harley, de que os mapas são "imagens carregadas de intenções e consequências que podem ser estudadas nas sociedades de seu tempo", de que mapas são instrumentos de saber-poder, se tornou restritivo na medida em que se observa que os mesmos são "instrumentos miméticos que vão além de seus fins pretendidos e se elevam acima das questões culturais que originalmente os moldaram" (Casti, 2005, p. 5). Os conceitos de autorreferencia e iconização enriquecem as análises desconstrutivistas, pois trazem nova perspectiva à essas análises. De uma forma extremamente reducionista, porém didática, o que muda é a forma unívoca de ver o mapa como "instrumento feito por alguém com um objetivo territorial", para um "instrumento feito por alguém com um objetivo territorial, mas que pode ser interpretado de outra forma e esta forma pode interferir/alterar

9 Plantas da Cidade de São Paulo mostrando seu desenvolvimento. Commissão Geographica e Geologica, 1922. Escala: 1:20.000. APESP. Disponível em: $<$ http://www.arquivoestado.sp.gov.br/site/acervo/repositorio_digital/mapa_carto/BR_APESP_IGC_IGG_CAR_ I_S_0207_001_001>. 
o território", como observado aqui, quando a falsa descrição da cidade, em 1897, acabou por conceitualizar a forma da cidade a partir desse momento.

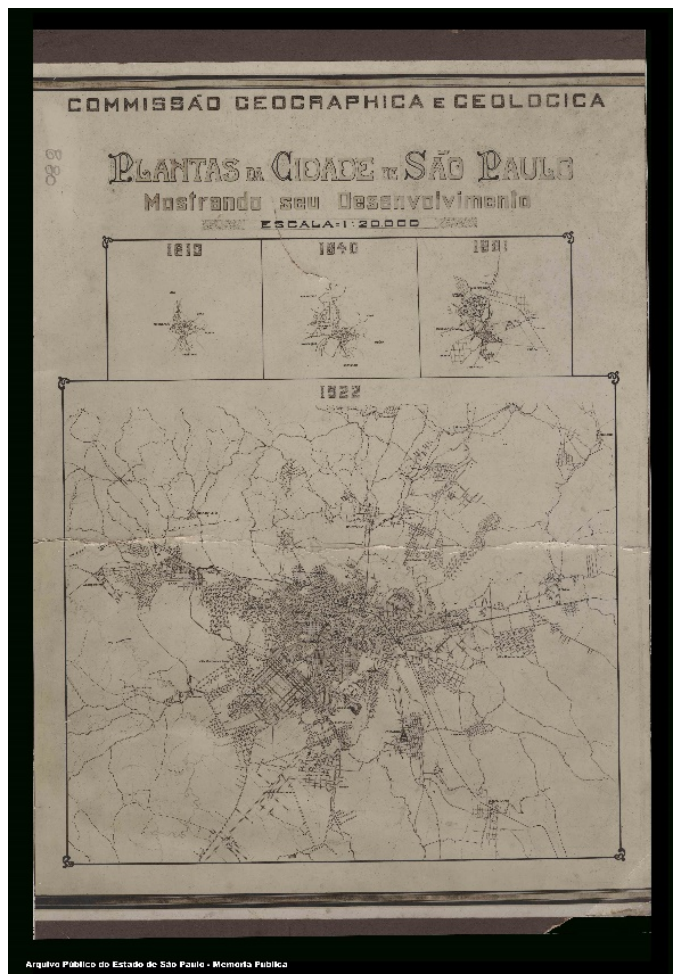

Figura 6. Uma das séries produzidas como cartazes pela CGGSP para serem enviadas às exposições nacionais e universais. Esta, feita para a Exposição Nacional de 1922, mantém o título das anteriores. "Plantas da cidade de S. Paulo mostrando seu desenvolvimento".

Com este trabalho, espera-se que as releituras dos documentos cartográficos apresentadas possam produzir mudanças na forma de utilização dos mapas históricos pelos pesquisadores das ciências humanas e sociais aplicadas. É importante que os pesquisadores olhem para o mapa como um documento de seu tempo, produzido com objetivos específicos e, principalmente, compreendam que seu estatuto de imagem vai muito mais além da simples e equivocada "verdade do território".

\section{Bibliografía}

Araujo, Iris Morais (2006). “Versões do 'progresso': a modernização como tema e problema do fotógrafo Militão Augusto de Azevedo (1862-1902)”, dissertação de Mestrado em Antropologia, São Paulo, FFLCH-USP. 
Barbosa, Maria do Carmo B. (1987). "Tudo como dantes no quartel de Abrantes. Práticas de produção do espaço na cidade de São Paulo (1890-1930)", tese de doutorado, FAU-USP, São Paulo.

Bernardini, Sidney Piochi (2007). "Construindo infraestruturas, planejando territórios: a Secretaria de Agricultura, Comércio e Obras Públicas do governo estadual paulista (1892-1926)2, tese de doutorado, FAU-USP.

Besse, Jean-Marc (2006). "Cartographie et pensée visuelle. Réflexions sur la schématisation graphique", Colóquio Expériences de terrain et compétences cartographiques. Maison Interuniversitaire des Sciences de l'homme - Alsace/Agence Nationale de la Recherche, Strasbourg, 9 juin 2006. Disponível em: $<$ http://hal.archives-ouvertes.fr/docs/00/25/67/10/PDF/Cartographie_et_pensee_visuelle.pdf $>$.

Besse, Jean-Marc (2009). Mapping, Constructing, Inventing: on de notion of project and its epistemology, First published in Le Goût du monde. Exercices de paysage. Actes Sud/ENSP, pp. 149-188. Disponível em: <https://univ-paris1.academia.edu/JeanMarcBesse>.

- (2014). Totalidade e dispersão. O atlas geográfico e as figuras da racionalidade. Texto elaborado para o curso: Escrever a história da geografia moderna. Questões epistemológicas, problemas historiográficos, FFLCH-USP, Trad. Eliane Kuvasney.

Brunet, Roger (1990). "Mondes nouveaux", tomo 1 da Géographie Universelle, Paris, Belin/RECLUS.

Casti, Emanuela (1998). L'ordine del mondo e la sua rappresentazione. Semiosi cartografica e autoreferenza, Milão, Unicopli.

(2005). "Towards a Theory of Interpretation: Cartographic Semiosis", Cartographica, vol. 40, no. 3, pp. 1-16.

Dutenkefer, Eduardo (2016). "Metodologia para um saber e um fazer geo-histórico: análise de espacialidades pretéritas utilizando instrumentos computacionais", $R e$ vista do Instituto de Estudos Brasileiros, ${ }^{\circ}$. 65, pp. 57-71.

Fonseca, Fernanda P. et al. (2016). "Cartografia digital geo-histórica: mobilidade urbana de São Paulo, de 1877 a 1930", Revista do Instituto de Estudos Brasileiros $\mathrm{n}^{\mathrm{0}}$. 65, pp. 131-166.

Fonseca, Fernanda Padovesi (2004). A Inflexibilidade do Espaço Geográfico. Uma questão para a Geografia, Tese de Doutorado, PPGH-USP.

Gagnebin, Jeanne-Marie (1993). "Do conceito de Mimesis no pensamento de Adorno e Benjamin", Perspectivas, São Paulo, no. 16, 1993, pp. 67-86.

Harley, J. Brian. (2009). "Mapas, saber e poder", Confins [Online], nº . 5. Disponível em: $<$ http://confins.revues.org/5724>

Harley, J. Brian (2005). La Nueva Naturaleza de los Mapas. Ensayos sobre la historia de la Cartografia, Fondo de Cultura, México. 
Harley, J. Brian and Woodword, David (orgs.) (1987). The History of Cartography, vol. 1, Chicago, University of Chicago Press. Disponível em: $<$ http://press.uchicago.edu/books/HOC/HOC_V1/Volume1.html>.

Kuvasney, Eliane (2015). "O mapa da fortificação da cidade de São Paulo por ocasião da Revolta Liberal de 1842. Contexto e usos atuais", Confins $\mathrm{n}^{\circ}$. 25. Disponível em: $<$ http://confins.revues.org/10524>.

Kuvasney, Eliane (2017). A representação da cidade de São Paulo nos albores do século XX. Os mapas como operadores na construção da cidade espraiada, tese doutorado em Geografia, FFLCH-USP, São Paulo. Disponível em: $<$ http://www.teses.usp.br/teses/disponiveis/8/8136/tde-26042018-135249/ptbr.php>.

Latour, Bruno (1985). "Les 'vues de l'esprit': une introduction à l'anthropologie des sciences et des techniques", Culture technique, $\mathrm{n}^{\circ} .14$.

Leite, Mateus Pavan de M. (2016). "Jules Martin, Litógrafo: catálogo iconográfico de um comerciante de imagens de São Paulo", dissertação de mestrado, IFCHUNICAMP, Campinas.

Lévy, Jacques e Lussault, Michel (2000). Logiques de l'espace, Esprit des lieux, Paris, Belin, Coleção Mappemonde.

Lima, Erly Caldas de (2013). O levantamento pioneiro do SARA Brasil: Histórico, tecnologia empregada e avaliação dos productos, dissertação de mestrado, POLIUSP, São Paulo.

Lussault, Michel (1995). "La ville Clarifiée", in Cambrézy, Luc e Maximy, René, La Cartographie em debat: representer ou convaincre, Paris, Éditions Karthala.

Lussault, Michel (2007). L'Homme Spatial. La construction sociale de l'espace humain, Paris, Édition du Seuil, 2007.

Mendes, Ricardo (2014). "S.A.R.A. Brasil: restituindo o Mapa Topográfico do Município de São Paulo", Informativo Arquivo Histórico de São Paulo, 10(37). Disponível em: <www.arquivohistorico.sp.gov.br>, acesso em jun/2015.

Morris, Charles (1985). Fundamentos de la teoría de los signos, Buenos Aires, Ediciones Paidós.

Oliva, Jaime e Fonseca, Fernanda Padovesi (2011). "Reflexões sobre o urbano, a cartografia e a iconografia: o caso da metrópole de São Paulo", Revista Geografia e Pesquisa, Ourinhos, vol. 5, no. 2, pp. 11-38.

Oliva, Jaime e Fonseca, Fernanda Padovesi (2016). “O 'modelo São Paulo': uma descompactação antiurbanidade na gênese da metrópole", Revista do Instituto de Estudos Brasileiros, $\mathrm{n}^{\circ} .65$, pp. 20-56.

Palsky, Gilles (2003). "L'Esprit des Cartes. Approches historiques, sémiologiques et sociologiques en cartographie. Diplôme d'habilitation à diriger des recherches", vol. 2, Memoire de Synthese, Université de Paris XII, Val de Marne. 
Panier, Louis (s/d), Ricouer et la Semiotique. Disponível em: $<$ http://halshs.archivesouvertes.fr/docs/00/35/36/43/DOC/Panier_Ricoeur_semotique.doc $>$, acesso em 28/02/2014.

Panofsky, Erwin (1976). Estudios sobre Iconologia, Madrid, Alianza Editorial.

Peirce, Charles S. (2005). Semiótica. São Paulo, Perspectiva.

Santos, Milton (2002). A natureza do espaço. São Paulo, Edusp.

Simoni, Lucia Noemia (2002). "O arruamento de terras e o processo de formação do espaço urbano no município de São Paulo, 1840-1930”, tese de doutorado, FAUUSP, São Paulo.

Souza, José Inácio de Melo (2014). “José de Sá Rocha: engenheiro municipal -uma trajetória pessoal e a formação de um corpo técnico para gestão da cidade". Informativo Arquivo Histórico de São Paulo, 9(35). Disponível em: <www.arquivohistorico.sp.gov.br>, acesso em 08/2015.

Turco, Angelo (2006). "Mythos e techne: a função intercultural do território na África subsaariana", Novos Cadernos NAEA, vol. 9, n. 1, pp. 5-24, Belém. 